\title{
GRAPHIC AND COGRAPHIC $\Gamma$-EXTENSIONS OF BINARY MATROIDS
}

\author{
Y.M. Borse \\ Department of Mathematics \\ Savitribai Phule Pune University \\ Pune-411007, India \\ e-mail: ymborse11@gmail.com \\ AND \\ Ganesh Mundhe \\ Army Institute of Technology \\ Pune-411015, India \\ e-mail: ganumundhe@gmail.com
}

\begin{abstract}
Slater introduced the point-addition operation on graphs to characterize 4-connected graphs. The $\Gamma$-extension operation on binary matroids is a generalization of the point-addition operation. In general, under the $\Gamma$-extension operation the properties like graphicness and cographicness of matroids are not preserved. In this paper, we obtain forbidden minor characterizations for binary matroids whose $\Gamma$-extension matroids are graphic (respectively, cographic).
\end{abstract}

Keywords: splitting, $\Gamma$-extension, graphic, cographic, minor.

2010 Mathematics Subject Classification: 05B35, 05C50, 05C83.

\section{REFERENCES}

[1] H. Azanchiler, Г-extension of binary matroids, ISRN Discrete Math. 2011 (2011) Article ID 629707. doi:10.5402/2011/269707

[2] H. Azanchiler, On extension of graphic matroids, Lobachevskii J. Math. 36 (2015) $38-47$. doi:10.1134/S1995080215010035 
[3] Y.M. Borse, M.M. Shikare and K.V. Dalvi, Excluded-minor characterization for the class of cographic splitting matroids, Ars Combin. 115 (2014) 219-237.

[4] H. Fleischner, Eulerian Graphs and Related Topics, Part 1, Vol. 1 (North Holland, Amsterdam, 1990).

[5] J.G. Oxley, Matroid Theory (Oxford University Press, Oxford, 1992).

[6] T.T. Raghunathan, M.M. Shikare and B.N. Waphare, Splitting in a binary matroid, Discrete Math. 184 (1998) 267-271. doi:10.1016/S0012-365X(97)00202-1

[7] M.M. Shikare and B.N. Waphare, Excluded-minors for the class of graphic splitting matroids, Ars Combin. 97 (2010) 111-127.

[8] M.M. Shikare, G. Azadi and B.N. Waphare, Generalized splitting operation for binary matroids and its applications, J. Indian Math. Soc. (N.S.) 78 (2011) $145-154$.

[9] P.J. Slater, A classification of 4-connected graphs, J. Combin. Theory Ser. B 17 (1974) 281-298.

doi:10.1016/0095-8956(74)90034-3

Received 12 October 2016

Revised 2 March 2017

Accepted 2 March 2017 